\title{
Biotechnology of Australian red-claw crayfish (Cherax quadricarinatus) juvenile ongrowing in recirculating aquaculture system
}

\author{
Dmitry Shumeyko ${ }^{1, *}$, Nikita Tsimbal $^{1}$, Aleksey Abramchuk ${ }^{1}$, Georgy Moskul $^{1}$ and \\ Aleksandr Taranik ${ }^{1}$ \\ ${ }^{1}$ Kuban State University, 149, Stavropolskaya str., 350040, Krasnodar, Russia
}

\begin{abstract}
As a result of the work done, the biotechnology of growing Australian red claw crayfish (Cherax quadricarinatus) juvenile in recirculating aquaculture system facilities was developed. The research work was carried out in the laboratory of advanced technologies in aquaculture on the basis of the business incubator the Federal State-Funded Educational Institution of Higher Education "Kuban State University". The composition of the material base necessary for the implementation of biotechnology is determined, growth rates are determined, an optimal diet is formed and optimal planting densities are determined. For the working process two recirculating aquaculture system units were used. As food we used: minced fish, sturgeon food, artemia nauplii, oatmeal, frozen bloodworm, dried gammarus. During 80 days, decades-long survival varied from 83.6 to $91.8 \%$. The average weight of individuals had changed from 0.03 to $5.10 \mathrm{~g}$. The coefficient of variation of this feature was in the permissible range and increased from 9.1 to $22.6 \%$. The total feed coefficient at a cost of $3387.3 \mathrm{~g}$ of feed per increase of $1347.7 \mathrm{~g}$ of biomass composed 2.5 units. Using the data obtained, it is possible to make primary calculations when organizing the cultivation of ARCC juveniles.
\end{abstract}

\section{Introduction}

The cultivation of decapods crustaceans in recent years shows active growth. In 2012, the amount of decapods in natural reservoirs exceeds their catch from natural body of water; their share is $23.1 \%$ [1]. In 20157.4 million tons of crustaceans were grown, in 2018 - 7.9 million tons [2].

One of the most actively cultivated crayfish in the world is the Australian red-claw crayfish (Cherax quadricarinatus) (ARCC). Adaptation and improvement work of its cultivation technology is progress $[3,4,5,6,7]$.

A special place in the aquaculture of crustaceans is occupied by the use of a recirculating aquaculture system (RAS) installations, which make it possible to control both the parameters of the maintenance environment and planting density, size-weight and sex composition $[8,9]$. Their use is the only possible way to grow warm-water species in

\footnotetext{
*Corresponding author: dima-shum-92@mail.ru
} 
regions where temperatures in natural reservoirs fall below the limits of acceptable and optimal temperatures for such species.

Currently almost no one is engaged in artificial reproduction with the subsequent sale of the resulting juveniles of the indicated object in Russia, despite the existing demand.

Low volumes of supply juveniles to the market are due to a combination of several factors: the small number of producers, low efficiency of incubation of spawn and the use of extensive methods of growing juveniles, leading to high mortality in the early stages of development.

Despite the experience and works, there is no complete picture. The optimal planting densities of ARCC individuals in the RAS and the effectiveness of multicomponent feeding remain in doubt. Therefore the study of fish breeding and biological specific features, the development of basic biotechnological principles and the creation of ARCC reproduction technology in artificial conditions using a closed water supply is relevant.

The purpose of this work is to study specific features of growing of juvenile Australian red-claw crayfish in the RAS.

\section{Materials and Methods}

The research work was carried out in the laboratory of advanced technologies in aquaculture on the basis of the business incubator of the Federal State-Funded Educational Institution of Higher Education "Kuban State University" from June till August 2017 with a break into decades during 80 days.

Studies were conducted using two RAS:

1. RAS № 1 (figure 1). The structure of this installation includes: four outgrowth plastic containers (trays), longitudinally divided in the middle by a partition, with a total area and volume of $1.34 \mathrm{~m}^{2}$ and $0.18 \mathrm{~m}^{3}$; combined block of mechanical and biological filtration with the volume of used water of $0.11 \mathrm{~m}^{3}$; pump; connecting polypropylene pipes and taps. Covering plates made of polystyrene foam were also used on each floor. It occupies an area of less than one square meter $-0.7 \mathrm{~m}^{2}$, with installation dimensions of $0.97 * 0.7 \mathrm{~m}$ and a height of $1.92 \mathrm{~m}$.

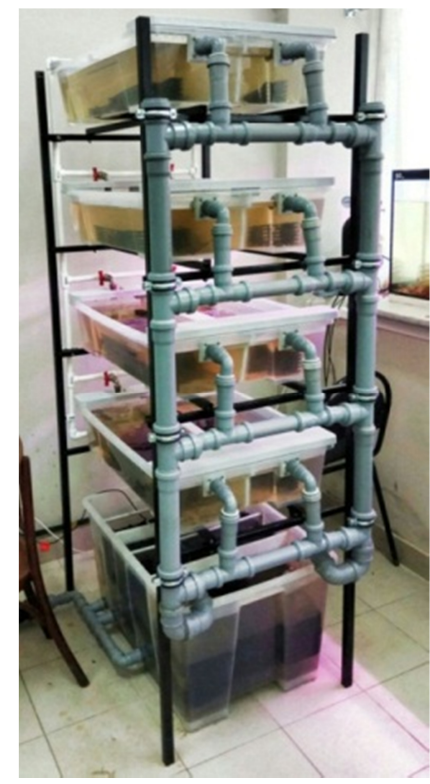

Fig. 1. RAS № 1. 
2. RAS № 2. It consists of the following elements: two round plastic tanks for keeping hydrobionts with a volume of $2.5 \mathrm{~m}^{3}$ and an area of $3.14 \mathrm{~m}^{2}$ each; sand filter for mechanical water purification of the brand "Astral pool", "ASTER 99" model with a throughput of 22 $\mathrm{m}^{3} / \mathrm{h}$ and a filtering area of $0.44 \mathrm{~m}^{2} ; 1.46 \mathrm{~m}^{3}$ submersible biological filter with 5 compartments, 4 of which are filled with a movable charge and the 5 th one, in which bactericidal treatment of water with a "Samsung" ultraviolet lamp, power $15 \mathrm{~W}$ was carried out; pump of the "Astral pool" brand with a productivity of $7 \mathrm{~m}^{3} / \mathrm{h}$; two "Hailea" compressors of the "ACO - 500" model with a productivity of $275 \mathrm{l} / \mathrm{min}$, one of which carries out aeration of compartments 3 and 4 of the biofilter and the other carries out aeration of water in tanks, and also connecting pipes made of polyvinyl chloride with a diameter of 100-160 mm.

When planning and implementing works, the indicators of planting densities and possible types of feeding described by a number of scientists were taken as the basis [ $8,10,11,12]$. As a result, taking into account the peculiarities of each RAS and the requirements for the conditions for the maintenance of ongrowing objects, there were developed the corrected schemes for the distribution of juveniles by tanks, ration and norms of their feeding, presented in tables 1 and 2.

Table 1. The scheme of planting juveniles in growth tanks by decades.

\begin{tabular}{|c|c|c|c|}
\hline Decade & Type of growth tank & Amount, pieces & Area, $^{\mathbf{2}}$ \\
\hline beginning & \multirow{3}{*}{ RAS tray № 1 } & 2 & 0.67 \\
\cline { 1 - 2 } \cline { 3 - 4 } & & 3 & 1.00 \\
\hline \multirow{nnny}{nnn}{} & \multirow{2}{*}{ RAS tank № 2 } & 4 & 1.34 \\
\hline $3-5$ & & 1 & 3.14 \\
\hline 6-8 & & 2 & 6.28 \\
\hline
\end{tabular}

As individuals grew, different types and the number of growing RAS tranks were used, having certain working areas: the RAS tray № $1-0.035 \mathrm{~m}^{2}$ and the RAS tray № $1-3.14$ $\mathrm{m} 2$.

The first two decades of cultivation were carried out in the RAS № 1, the subsequent in the RAS № 2 .

The following objects were used as fodder: minced fish from blue whitings, sturgeon fodder (Coppens vital (0.8-1.2 mm) with a protein content of $46.0 \%$, fat $10.0 \%$; until the third decade it was grinded in a coffee grinder), artemia nauplii, oatmeal, frozen bloodworm, dried gammarus (soaked in boiling water before application). The feeding was produced according to the following scheme (table 2):

Table 2. Diet and feeding scheme for juveniles.

\begin{tabular}{|c|c|c|c|c|c|c|c|c|c|c|c|}
\hline Decade & \multicolumn{2}{|c|}{$\mathbf{1}$} & $\mathbf{2}$ & \multicolumn{2}{|c|}{$\mathbf{3}$} & $\mathbf{4}$ & $\mathbf{5}$ & $\mathbf{6}$ & $\mathbf{7}$ & $\mathbf{8}$ \\
\hline \multirow{2}{*}{ Daily rate, \% } & \multicolumn{2}{|c|}{35} & 25 & \multicolumn{2}{|c|}{20} & 20 & 18 & \multicolumn{2}{|c|}{12} & 12 & 10 \\
\hline \multirow{3}{*}{ Daily rate of the component, \% } & MF & 65 & 65 & MF & 60 & 60 & 60 & MF & 60 & 60 & 60 \\
\cline { 2 - 13 } & SF & 30 & 30 & SF & 20 & 20 & 20 & SF & 10 & 10 & 10 \\
\cline { 2 - 12 } & \multirow{2}{*}{ A } & \multirow{2}{*}{5} & 5 & O & 10 & 10 & 15 & O & 20 & 20 & 20 \\
\cline { 4 - 11 } & & & & B & 10 & 10 & 10 & G & 10 & 10 & 10 \\
\hline
\end{tabular}


Note: MF — minced fish, SF - sturgeon fodder, A - artemia nauplii, O - oatmeal, B - bloodworm, G - Gammarus.

During the experiment, the daily feed rate was changed from 35 to $10 \%$.

To reduce the level of cannibalism the division of juveniles into size groups and two types of shelters were used. The first one is for juveniles up to $0.1-0.2 \mathrm{~g}-$ it is a six-storied structure of polycarbonate strips. One such structure provides crayfish cells (shelters) from 280 to 350 pieces. The second is for juveniles which are more than $0.1-0.2 \mathrm{~g}$; it is made of blocks of rigid plastic mesh with 56 cells. A more detailed description is not provided since the developed shelters are at the stage of intellectual property protection.

The main hydrochemical parameters of water were checked by colorimetric tests of Sera and Api and were within the limits of fish breeding norms. The water temperature for the period was in the range of $26.0-28.0^{\circ} \mathrm{C}$.

At the beginning of the experiment 600 juveniles obtained from three females were involved. Each decade weighing, recounting the amount of individuals and adjustment of feeding were carried out. Weighing of ARCC juveniles was carried out with an accuracy of $0.01 \mathrm{~g}$, feed - up to $0.1 \mathrm{~g}$ on an electronic scales.

Statistical processing and graphic presentation of the results was made according to generally accepted methods using the software packages "Microsoft Excel 2007".

To determine the mass accumulation coefficient (1) and the biomass growth (2) the formula was used

$$
\begin{aligned}
& \mathrm{K}_{\mathrm{m}}=\left[3\left(\mathrm{M}_{\mathrm{k}}^{1 / 3}-\mathrm{M}_{0}^{1 / 3}\right)\right] / \Delta \mathrm{t} \\
& \mathrm{D} \%=(\mathrm{M \kappa}-\mathrm{M} 0)^{*} 100 \% / \mathrm{M} 0
\end{aligned}
$$

In which $M_{\kappa}$ - final mass value; $M_{0}$ - initial mass value; $\Delta t$ - observation time.

\section{Results}

As a result of the studies it was found that during 80 days the survival rate over the decades ranged from 83.6 to $91.8 \%$. In absolute terms out of 600 pieces by the end of the experiment 268 remained (44.6\%). The landing densities at which survival was lower than $90.0 \%$ should be noted. At $365.9 \mathrm{pcs} / \mathrm{m}^{2}$ for juveniles with an average weight of $0.15 \mathrm{~g}$ the survival rate was $83.6 \%$ and $84.9 \%$ at $120.0 \mathrm{pcs} / \mathrm{m}^{2}$ for $1.21 \mathrm{~g}$, respectively. The average weight of individuals varied from 0.03 to $5.10 \mathrm{~g}$. The coefficient of variation of this trait was in the permissible range and increased in time from 9.1 to $22.6 \%$ (table 3 ).

\begin{tabular}{|c|c|c|c|c|}
\hline \multirow{2}{*}{ Decade } & \multirow{2}{*}{$\frac{\frac{\bar{x} \pm m_{x}}{\min -\max } \cdot g}{C V . \%}$} & \multicolumn{2}{|c|}{ Survival } & \multirow{2}{*}{$\begin{array}{l}\text { Stocking density } \\
\text { piece } / \mathbf{m}^{2}\end{array}$} \\
\hline & & pieces & $\%$ & \\
\hline beginning & $\frac{0.03 \pm 0.001}{\frac{0.03-0.05}{9.1}}$ & 600 & 100 & 895.5 \\
\hline 1 & $\frac{0.07 \pm 0.001}{\frac{0.06-0.08}{10.4}}$ & 543 & 90.5 & 543.0 \\
\hline 2 & $\frac{0.15 \pm 0.001}{\frac{0.13-0.17}{16.2}}$ & 490 & 90.3 & 365.9 \\
\hline 3 & $\begin{array}{c}0.29 \pm 0.002 \\
\underline{0.22-0.36} \\
\end{array}$ & 454 & 83.6 & 144.6 \\
\hline
\end{tabular}

Table 3. Fish and biological indicators of rearing of a ARCC juvenile. 


\begin{tabular}{|c|c|c|c|c|}
\hline & 17.2 & & & \\
\hline 4 & $\frac{0.61 \pm 0.006}{\frac{0.47-0.76}{18.8}}$ & 415 & 91.5 & 132.3 \\
\hline 5 & $\frac{1.21 \pm 0.011}{\frac{0.99-1.48}{17.8}}$ & 377 & 90.7 & 120.0 \\
\hline 6 & $\frac{2.13 \pm 0.023}{\frac{1.69-2.54}{19.6}}$ & 320 & 84.9 & 50.9 \\
\hline 7 & $\frac{3.40 \pm 0.038}{\frac{2.70-4.12}{19.4}}$ & 294 & 91.8 & 46.8 \\
\hline 8 & $\frac{5.10 \pm 0.070}{\frac{3.87-6.35}{22.6}}$ & 268 & 91.2 & - \\
\hline
\end{tabular}

Note: $\bar{x}$ - average; $m_{x}$ - standard error of the mean; $C V$ - coefficient of variation.

Information on the dynamics of biomass and feed costs is presented in table 4 . The biomass of juveniles during the experiment increased from 18.0 to $1365.7 \mathrm{~g}$. The table shows a systematic increase in mass accumulation coefficient from 0.22 to $0.33-0.36$ units by the end of the experiment, but there is also an increase in the rate to 0.37 and 0.47 units in the middle (4-5 decades). The relative growth trend was decreasing from 52.6 to $26.9 \%$.

Table 4. Dynamics of biomass of ARCC juvenile and indicators of feed costs.

\begin{tabular}{|c|c|c|c|c|c|c|c|}
\hline Decade & Mk. g & D. g & Average daily. D. g & $\mathbf{K}_{\mathbf{m}} \cdot \mathbf{u n i t}$ & $\mathbf{D .} \mathbf{\%}$ & $\begin{array}{c}\text { Consumption. } \\
\mathbf{g}\end{array}$ & $\begin{array}{c}\mathbf{F . r .} \\
\text { unit }\end{array}$ \\
\hline beginning & 18.0 & - & - & - & - & & \\
\hline 1 & 38.0 & 20.0 & 2.00 & 0.22 & 52.6 & 63.0 & 3.1 \\
\hline 2 & 73.55 & 35.5 & 3.55 & 0.25 & 48.3 & 95 & 2.7 \\
\hline 3 & 131.64 & 58.1 & 5.81 & 0.27 & 44.1 & 147.1 & 2.5 \\
\hline 4 & 253.37 & 121.7 & 12.17 & 0.37 & 48.0 & 263.3 & 2.2 \\
\hline 5 & 455.85 & 202.5 & 20.25 & 0.41 & 44.4 & 456.1 & 2.3 \\
\hline 6 & 681.27 & 225.4 & 22.54 & 0.33 & 33.1 & 547 & 2.4 \\
\hline 7 & 998.31 & 317.0 & 31.70 & 0.36 & 31.8 & 817.5 & 2.6 \\
\hline 8 & 1365.7 & 8 & 1365.7 & 367.4 & 26.9 & 998.3 & 2.7 \\
\hline
\end{tabular}

Note: Average daily D - daily average biomass increase; Consumption - feed consumption for the period; F.r. - feed ratio.

During the experiment, the accumulation of a certain amount of organic residues in containers for growing from the time of uneaten food was noticed. The total feed coefficient at a cost of $3387.3 \mathrm{~g}$ of feed per increase of $1347.7 \mathrm{~g}$ of biomass was 2.5 units. The minimum feed ratios were recorded in 4-5 decades and are equal to 2.2 and 2.3 units respectively and the maximum is 3.1 units. in the first ten days.

\section{Discussion}

The selection of optimal planting densities of ARCC individuals in the RAS and feeding ration has a great influence on the efficiency of cultivation.

The influence of the first factor can be seen in changes in survival in the third decade, when during a landing of juveniles of $365.9 \mathrm{pcs} / \mathrm{m}^{2}$ in four RAS trays unit No. 1 it decreased to a minimum of $83.6 \%$ and increased to a maximum of $91.5 \%$ when transplanted to the RAS No. 2 to the tank, which has a significantly larger area. As a rule, 
the main studies by scientists were carried out with already grown juveniles. In one of the works of Borisov and Nikonova [13], 66-68\% survived after 60 days during the landing of juveniles weighing $2.12-3.62 \mathrm{~g}$ of $190 \mathrm{pcs} / \mathrm{m}^{2}$ after 60 days. In our studies the survival rate of juveniles of the same size during 30 days was $83.4 \%$. Considering the dynamics in one time interval survival can be considered identical despite the fact that landing densities differed in almost 4 times. In addition to mortality, one must also take into account growth indicators, which cannot be correlated in this case. Considering cases with the same mortality at similar time intervals and landing densities, one in which individuals have large size-weight characteristics will be more effective.

If we compare the results with other work [14], with a similar period of growth (60 days), starting weights of $0.25 \mathrm{~g}$ and ranges of planting densities of $120-160 \mathrm{pcs} / \mathrm{m}^{2}$, you can notice that the survival rate was $56.9-61.1 \%$ and the final average weight was $2.44-2.81$ $\mathrm{g}$ versus our $59.0 \%$ and $5.1 \mathrm{~g}$, respectively. It is important to understand that such a result was achieved only by further planting of ARCC juvenile.

The importance of proper diet selection can be seen in the reduction in survival to $84.7 \%$ in the fifth decade when replacing frozen bloodworms with gammarus and increasing the proportion of oatmeal in the daily feeding rate. A subsequent return to normal indicates the need for a smoother replacement of these types of feed.

Indicators of feed coefficient of 2.2-3.1 units of multicomponent feeds versus 0.7-1.7 units of granular feed $[14,15]$ and operational difficulties make us think about the appropriateness of its use. To make a final decision on the preferred method of feeding, it is necessary to calculate the cost of feed facilities that the enterprise may have.

An important component of the effective cultivation of ARCC juvenile is the use of various intensification techniques. A part of our research was devoted to the development of one of them. The possibility of using water with a reduced deuterium content ( $86 \mathrm{mg} / 1$, at $310 \mathrm{mg} / \mathrm{l}$ in the control) was studied.

Its application allows to: get juveniles with the weight of $6.14 \mathrm{~g}$ in 55 days; increase survival by $7.5 \%$, increase weight by $10.9 \%$, increase biomass by $39.1 \%$ and reduce the feed coefficient [15].

\section{Conclusions}

As a result of data analysis and material processing it was found that when making small changes in the landing density you can get a more significant result. In this regard, table 5 was compiled with recommended landing densities.

Table 5. Landing density.

\begin{tabular}{|c|c|}
\hline Decade & Recommended planting density, pes $/ \mathbf{m}^{\mathbf{2}}$ \\
\hline beginning & 890 \\
\hline 1 & 540 \\
\hline 2 & 300 \\
\hline 3 & 150 \\
\hline 4 & 130 \\
\hline 5 & 100 \\
\hline 6 & 70 \\
\hline 7 & 60 \\
\hline 8 & - \\
\hline
\end{tabular}

An experimental multi-tiered installation (RAS №1) was developed and assembled, in which it is possible to overexposure females during the incubation of eggs and rearing young in the early stages of life. When installing additional partitions up to 16 females are possible during the incubation period of eggs. It was found that the use of multi-tiered 
installations with low growth capacities and a water thickness of 6 to $15 \mathrm{~cm}$ is more appropriate when working with crustaceans, for which the bottom area and not the volume of water is important.

Using the data obtained, it is possible to make primary calculations when organizing the cultivation of ARCC juvenile.

\section{References}

1. FAO 2013. Cherax quadricarinatus (Von Martens, 1868) (The State of World Fisheries and Aquaculture, Rome, 2012) http://www.fao.org

2. Fishery and Aquaculture Statistics. Global aquaculture production 1950-2015 (FishstatJ) (FAO Fisheries and Aquaculture Department, Rome, 2017) http://www.fao.org/fishery/statistics/software/fishstatj/en

3. N.C. Prymaczok, A. Chaulet, D.A. Medesani, E. Marcelo Rodríguez, Aquaculture 334-337, 176-181 (2012) https://doi.org/10.1016/j.aquaculture.2011.12.032

4. C. Tropea, Y. Piazza, L.S. López Greco, Aquaculture 302(1-2), 49-56 (2010) https://doi.org/10.1016/j.aquaculture.2010.01.027

5. N.S. Calvo, L. Stumpf, S. Pietrokovsky, L.S. López Greco, Aquaculture 319(3-4), 355-362 (2011) https://doi.org/10.1016/j.aquaculture.2011.06.033

6. L. Stumpf, N.S. Calvo, S. Pietrokovsky, L.S. López Greco, Aquaculture 304(1-4), 3441 (2010) https://doi.org/10.1016/j.aquaculture.2010.03.011

7. V.E. Viau, J.M. Ostera, A. Tolivia and others, Aquaculture 324-325, 70-78 (2012) https://doi.org/10.1016/j.aquaculture.2011.10.009

8. G.M. García-Ulloa, M.R. Pérez-Moreno, D. Rodríguez-González and others, Journal of Applied Aquaculture 24(1), 8-15

https://doi.org/10.1080/10454438.2012.650599

9. A. Drengstiga, A. Bergheim, Aquacultural Engineering 53, 14-18 (2013) https://doi.org/10.1016/j.aquaeng.2012.11.007

10. L. Stumpf, N.S. Calvo, S. Pietrokovsky, L.S. López Greco, Aquaculture 304(1-4), 3441 (2010) https://doi.org/10.1016/j.aquaculture.2010.03.011

11. L. Stumpf, N.S. Calvo, F. Castillo Díaz, W.C. Valenti, L.S. López Greco, Aquaculture 319(1-2), 98-104 (2011) https://doi.org/10.1016/j.aquaculture.2011.06.029

12. L. Stumpf, C. Tropea, L.S. López Greco, Aquaculture 433, 404-410 (2014) https://doi.org/10.1016/j.aquaculture.2014.06.037

13. R.R. Borisov, I.N. Nilonova, Marine Biological Journal 3(3), 3-12 (2018)

14. V.A. Aristangalieva, Development of technology for growing Australian red claw crab planting stock (Cherax quadricarinatus) in a RAS: dis. (Moscow, 2017)

15. D.V. Shumeiko, D.Y. Rotar, II All-Russian Scientific and Practical Conference "Actual Aspects of the Development of Rural (Agrarian) Tourism in Russia», 152-157 (Krasnodar, 2018) 